\title{
DLC-Coated Ferroelectric Membranes as Vascular Patches: Physico-Chemical Properties and Biocompatibility
}

\author{
Yuri Yuriev ${ }^{1,2}$, Semen Goreninskii ${ }^{3}$, Artem Runts ${ }^{1}$, Elisaveta Prosetskaya ${ }^{1}$, Evgenii Plotnikov ${ }^{4}$, \\ Darya Shishkova ${ }^{5}$, Yulia Kudryavtseva ${ }^{5}$ and Evgeny Bolbasov $1,2, *$ (i) \\ 1 B.P. Veinberg Research and Educational Centre, Tomsk Polytechnic University, 634050 Tomsk, Russia; \\ yurjev@tpu.ru (Y.Y.); artemshift@tpu.ru (A.R.); eap47@tpu.ru (E.P.) \\ 2 Microwave Photonics Laboratory, V.E. Zuev Institute of Atmospheric Optics SB RAS, 634055 Tomsk, Russia \\ 3 N.M. Kizhner Research and Educational Centre, Tomsk Polytechnic University, 634050 Tomsk, Russia; \\ sig1@tpu.ru \\ 4 Research School of Chemistry \& Applied Biomedical Sciences, Tomsk Polytechnic University, \\ 634050 Tomsk, Russia; plotnikovev@tpu.ru \\ 5 Research Institute for Complex Issues of Cardiovascular Diseases, 650002 Kemerovo, Russia; \\ Shishkova@cardio.kem.ru (D.S.); kudrua@cardio.kem.ru (Y.K.) \\ * Correspondence: Ebolbasov@gmail.com
}

\section{check for} updates

Citation: Yuriev, Y.; Goreninskii, S.; Runts, A.; Prosetskaya, E.; Plotnikov, E.; Shishkova, D.; Kudryavtseva, Y.; Bolbasov, E. DLC-Coated

Ferroelectric Membranes as Vascular Patches: Physico-Chemical Properties and Biocompatibility. Membranes 2021, 11, 690. https://doi.org/ 10.3390/membranes11090690

Academic Editor: Maria

Helena Casimiro

Received: 16 August 2021

Accepted: 31 August 2021

Published: 7 September 2021

Publisher's Note: MDPI stays neutral with regard to jurisdictional claims in published maps and institutional affiliations.

Copyright: (c) 2021 by the authors. Licensee MDPI, Basel, Switzerland. This article is an open access article distributed under the terms and conditions of the Creative Commons Attribution (CC BY) license (https:// creativecommons.org/licenses/by/ $4.0 /)$.
Abstract: In this paper, the results on the fabrication of ferroelectric membranes as vascular patches with modified surfaces are presented. For the modification of a membrane surface contacting blood, DLC coating was deposited using the pulsed vacuum arc deposition technique. The physico-chemical properties and cytotoxicity of the membranes modified under various conditions were studied. It was found that DLC coatings do not affect membrane microstructure, preserving its crystal structure as well as its high strength and elongation. It was revealed that an increase in the capacitor storage voltage results in the rise in $\mathrm{sp}^{2}$ - and sp-hybridized carbon concentration, which makes it possible to control the chemical structure and surface energy of the modified surface. The experiments with 3T3L1 fibroblasts showed no toxic effects of the materials extracts.

Keywords: ferroelectric membranes; DLC coatings; vascular patches

\section{Introduction}

According to the World Health Organization, cardiovascular disease (particularly atherosclerosis (stenosis) of the carotid artery) remains one of the main causes of mortality in developed and developing countries [1,2]. The outbreak of the COVID-19 infection makes the problem even more relevant [3]. One of the main approaches for the restoration of carotid artery permeability is reconstruction with vascular patches after surgical thrombus removal [4]. Autologous veins remain the gold standard of vascular patches, but their deficiency significantly limits the availability of such medical help [5]. For that reason, researchers around the world are looking for novel materials for effective carotid artery restoration.

Owing to their high strength, non-toxicity, chemical stability, and hemocompatibility, electrospun fibrous polymer membranes made of polyvinylidene fluoride and its copolymers, trifluoroethylene (VDF-TrFE) and tetrafluoroethylene (VDF-TeFE), appear to be promising materials for the development of vascular patches [6]. The ferro- and piezoelectric properties of such membranes enhance the adhesion and proliferation of various cells, thus improving vascular patch endothelialization and decreasing the possibility of post-surgical complications [7-9].

One of the key problems with membranes made of PVDF and its copolymers is their thrombogenicity. In order to overcome this drawback, various strategies for the modification of membranes resulting in the hindrance of protein adsorption have been proposed. Among the common modification approaches are: the formation of organic coatings [10], 
ion irradiation [11], polydopamine-mediated atom transfer radical polymerization [12], and composite membrane fabrication [13].

The fabrication of diamond-like carbon (DLC) coatings on the membrane surface appears to be a promising approach for the reduction in vascular patch thrombogenicity induced by PVDF and its copolymers. Owing to the properties of DLC coatings, such as high hardness, low frictional coefficient, high wear and corrosion resistance, chemical inertness, high electrical resistivity, antibacterial activity, and high hemo- and biocompatibility, they can be applied to the surface of blood-contacting devices (vascular grafts, coronary stents, heart valves, catheters, hemodialyzers, and heart-lung bypass systems) in order to lower their thrombogenicity [14-17]. Thus, DLC coatings formed on the surface of blood-contacting polymer ferroelectric vascular patches may reduce their thrombogenicity. The further modification of DLC coatings by physical and chemical approaches imparts them with antithrombogenic properties, and stimulates the adhesion and proliferation of various cell types $[18,19]$. Thus, DLC coatings may be applied in order to decrease the thrombogenicity of the inner surface of the vascular patch, as well as for the enhanced endothelialization of its outer surface.

The following techniques are used for the deposition of DLC coatings on metal and ceramic implants: magnetron sputtering, ion beam deposition, vacuum-arc evaporation, pulsed laser deposition, mass selected ion beam deposition, and plasma-based ion implantation $[20,21]$. The listed methods of DLC coating fabrication require accelerating potential to the substrate, resulting in a significant rise in the substrate temperature, or they do not have a sufficient deposition rate. These factors limit the applicability of the listed techniques for the deposition of coatings on the surface of ultrathin fibrous polymer membranes.

The pulsed vacuum arc deposition method appears to be a promising approach for the fabrication of DLC coatings on the surface of polymer membranes [22,23]. This method allows for the generation of carbon plasma with ion energy in the range of $40-90 \mathrm{eV}$ by changing the capacitor storage voltage, does not require accelerating potential to the substrate, provides a high rate of condensate formation (up to $1 \times 10^{4} \AA / \mathrm{s}$ ), and the substrate temperature does not exceed $70^{\circ} \mathrm{C}$ [24]. These features make the pulsed vacuum arc deposition method suitable for the deposition of DLC coatings on the surface of vascular patches made of PVDF and its copolymers. However, until now, there have been no reports on the application of DLC coatings on the surface of vascular patches made of PVDF and/or its copolymers. The physico-chemical and biomedical properties of the modified membranes and the DLC coatings formed on their surface have not been reported. This is limiting the application of DLC coatings for the modification of vascular patches, hindering the utilization of these membranes in clinical practice, and restricting the application of pulsed vacuum arc deposition as a multifunctional method for the treatment of various surfaces (metals, ceramics, and polymers). In the present work, we report the possibility of DLC coating deposition on the surface of ferroelectric polymer membranes by means of pulsed vacuum arc deposition, as well as the physico-chemical properties and biocompatibility of the modified membranes, for the first time.

\section{Materials and Methods}

\subsection{Electrospinning of VDF-TeFE Membranes}

The membranes were prepared from a $6 \%$ wt. solution of VDF-TeFE copolymer (VDF/TeFE ratio 80/20, Halopolymer, Moscow, Russia) in acetone. Membrane fabrication was conducted using the electrospinning technique (NANON-01A, MECC CO., LTD, Fukuoka, Japan) on an aluminum cylindrical collector with a $200 \mathrm{~mm}$ length and a $100 \mathrm{~mm}$ diameter. The distance between the injector ( $24 \mathrm{G}$ needle) and the assembly manifold was $90 \mathrm{~mm}$. The voltage of the injector was $25 \mathrm{~kW}$. The flow rate of the spinning solution was $4 \mathrm{~mL} / \mathrm{h}$, and the assembly speed was $200 \mathrm{rpm}$. To remove the residual solvents, the fabricated membranes were stored in a VD 115 vacuum furnace (Binder, Tuttlingen, Germany) at a temperature of $100^{\circ} \mathrm{C}$ and a 0.1 Pa pressure for $24 \mathrm{~h}$. 


\subsection{Deposition of DLC Coatings by the Pulsed Vacuum Arc Deposition Technique}

Prior to the DLC coating formation, the membranes were placed on a metal substrate fixed in a special holder that provides rotation around itself and the setup perimeter for the formation of a uniform coating (Figure S1). The formation of DLC coatings on the membrane surfaces was conducted by the pulsed vacuum arc deposition method with the sputtering of a high-purity graphite $(99.99 \%)$ cathode. The following parameters were applied during the coating deposition: a striking voltage of $400 \mathrm{~V}$, a pulse frequency of $3 \mathrm{~Hz}, 3000$ pulses per sample, and a minimum target-to-membrane distance of $250 \mathrm{~mm}$. The pulsed arc was powered by a $2000 \mu \mathrm{F}$ capacitor bank. Four sample groups were formed with respect to the used capacitor storage voltage $(150,200,250$, and $300 \mathrm{~V})$. Non-modified samples were used as a control group. Before the DLC coating deposition, the samples were cleaned with argon ions. An ion source with Hall electron drift was used for cleaning with the following parameters: an ion source voltage of $1 \mathrm{kV}$, a discharge current of $30 \mathrm{~mA}$, a chamber pressure of $2.1 \times 10^{-2} \mathrm{~Pa}$, and a treatment time of $40 \mathrm{~s}$.

\subsection{Membrane Characterization}

\subsubsection{Scanning Electron Microscopy (SEM)}

The morphology of the membranes was investigated by scanning electron microscopy (SEM) (VEGA 3 SBH, Tescan, Warrendale, PA, USA). The fiber diameter of the membranes was determined from the SEM images out of 10 different fields of view using Image J 1.38 software (National Institutes of Health, Bethesda, MD, USA). To calculate an average diameter, at least 350 fibers were measured.

\subsubsection{Tensile Strength and Relative Elongation}

The tensile strength and the relative elongation of the samples were investigated according to the recommendations of ISO 9073.3:1989 using the Instron 3344 tensile testing machine (Instron, Norwood, MA, USA) with a sample preload of $0.1 \mathrm{~N}$ and a crosshead speed of $10 \mathrm{~mm} / \mathrm{min}$.

\subsubsection{X-ray Diffraction Analysis (XRD)}

The crystal structure of the membranes was investigated using the X-ray diffraction method with an XRD 6000 diffractometer (Shimadzu, Kyoto, Japan). The average size of the crystallites $\left(l_{c}\right)$ was calculated using the Debye-Scherrer Equation (1):

$$
l_{c}=\frac{k \lambda}{\cos \theta \beta}
$$

where $\lambda$ is the wavelength of the incident radiation (Cu K-alpha, $\lambda=1.54056 \AA$ ), $\beta$ is the width of the reflection at a half height (FWHM), $\theta$ is the angle of the diffraction, and $k=0.9$. The estimation of the FWHM parameter was performed by interpolating the X-ray pattern using a Gauss function (Origin 2021, Origin Lab., Northampton, MA, USA).

\subsubsection{Raman Spectroscopy}

Raman spectra were taken using an InVia spectrometer (Renishaw, Gloucester, UK) equipped with a DM 2500 M microscope (Leica, Wetzlar, Germany) with a 50X objective. Lasers with the power of $100 \mathrm{~mW}$, wavelengths of $532 \mathrm{~nm}$, and a spectral resolution of $2 \mathrm{~cm}^{-1}$ were used. A spectral range of $500-2500 \mathrm{~cm}^{-1}$ was considered. The Raman spectra were deconvoluted using Gaussian line fitting (Origin 2021, Origin Lab., Northampton, MA, USA). The fitting parameters were used to calculate the Raman parameters, including band position and the spectral intensity ratios $\mathrm{I}_{\mathrm{D}} / \mathrm{I}_{\mathrm{G}}$ and $\mathrm{I}_{\max } / \mathrm{I}_{\mathrm{C}}$.

\subsubsection{Wettability and Surface Energy}

The samples' wettability was characterized by depositing $3 \mu \mathrm{L}$ drops of polar (Milli-Q water $\left(\mathrm{H}_{2} \mathrm{O}\right)$ ) and non-polar (diiodomethane $\left(\mathrm{CH}_{2} \mathrm{I}_{2}\right)$ ) liquids using an Easy Drop (Easy 
Drop, KRÜSS GmbH, Hamburg, Germany) contact angle measurement system. Droplets were placed at different positions on samples and images were captured after a $2 \mathrm{~min}$ deposition of each drop. According to the results of the contact angle measurement, surface free energy $(\sigma)$ and its dispersive $\left(\sigma^{\mathrm{D}}\right)$ and polar $\left(\sigma^{\mathrm{P}}\right)$ components were calculated using the Owens-Wendt-Rabel-Kaelble (OWRK) method.

\subsubsection{Cytotoxicity of Membrane Extracts}

The study of the interaction of the obtained membranes with cells in vitro was carried out using mouse embryonic fibroblasts 3T3L1. Sterile membrane samples with a diameter of $12 \mathrm{~mm}$ were placed into the wells of 24 -well plates and filled by $100 \mu \mathrm{L}$ cell growth media per well. The samples were left for 5 days in a $\mathrm{CO}_{2}$ incubator at $37^{\circ} \mathrm{C}$ for extraction. For all cell experiments, we used the same media, DMEM (Gibco, Gaithersburg, MD, USA), supplemented with the glutamine supplement GlutaMAX (Gibco, Gaithersburg, MD, USA), $10 \%$ fetal bovine serum One Shot ${ }^{\circledR}$, (Thermo Fisher Scientific, São Paulo, Brazil), and antibiotics (penicillin/streptomycin mixture) (Paneko, Moscow, Russia). After extraction, media were used for cell growth. A medium without polymer disks was used as a control and kept in the same conditions for 5 days. The cells were cultured for 24, 72, and $168 \mathrm{~h}$ in an atmosphere containing $5 \% \mathrm{CO}_{2}$ at a temperature of $37^{\circ} \mathrm{C}$. After incubation, media from each sample were used for cytotoxicity and cell growth in the MTT assay. To perform the MTT test, the medium in the plate was replaced with a solution of 3-(4,5-dimethylthiazol-2yl) -2,5-diphenyl-2H-tetrazolium bromide (MTT) at a concentration of $0.45 \mathrm{mg} / \mathrm{mL}$, and the plate was placed in a thermostat for $4 \mathrm{~h}$. The MTT solution was then removed and DMSO was added to dissolve the formazan. Next, the optical density was measured at a wavelength of $570 \mathrm{~nm}$, and the viability calculation was performed and presented as a percentage of the control group.

The absolute number of cells per $1 \mathrm{~mm}^{2}$ of the surface was evaluated using a fluorescence microscopy system (AxioVert.A1, Carl Zeiss, Oberkochen, Germany). Cells were stained with vital fluorescent dyes Calcein AM $0.5 \mu \mathrm{g} / \mathrm{mL}$ (Abcam, Cambridge, MA, USA) for the green staining of the cells' cytoplasm, and Hoechst $333421 \mu \mathrm{g} / \mathrm{mL}$ (Sigma-Aldrich, St. Louis, MI, USA) for the blue staining of the nuclei of all adhered cells. The dyes were applied to the samples $15 \mathrm{~min}$ before the microscopy. Image processing was performed using ZEN pro software (Carl Zeiss, Oberkochen, Germany). Cells were counted using Image 1.38 software (National Institutes of Health, Bethesda, MD, USA) from 10 different fields of view. The studies were performed on 5 samples of each studied group in triplicate using 10 randomly selected fields of view for each group. Cells cultured in media without material extraction were used as a control.

\subsubsection{Statistical Analysis}

Statistical analysis was performed in GraphPad Prism 8.00 (GraphPad Software, La Jolla, CA, USA). The data are shown as mean (SD) \pm standard deviation (SD).

\section{Results and Discussion}

\subsection{DLC Coatings Deposition}

The photographs of the front and back sides of the membranes before and after the deposition of the DLC coating under various capacitor storage voltages are presented in Figure 1. The front and back sides of the original polymer membrane were not different from each other and had a uniform white color. Coating deposition resulted in the change of the front side color from brownish ( $150 \mathrm{~V})$ to black (300 V). Macro defects such as burns and melting were not observed. The samples' color was uniform. The color of the back side of the sample was not changed under all the tested deposition parameters. Thus, single-side modification of the membrane is possible. 


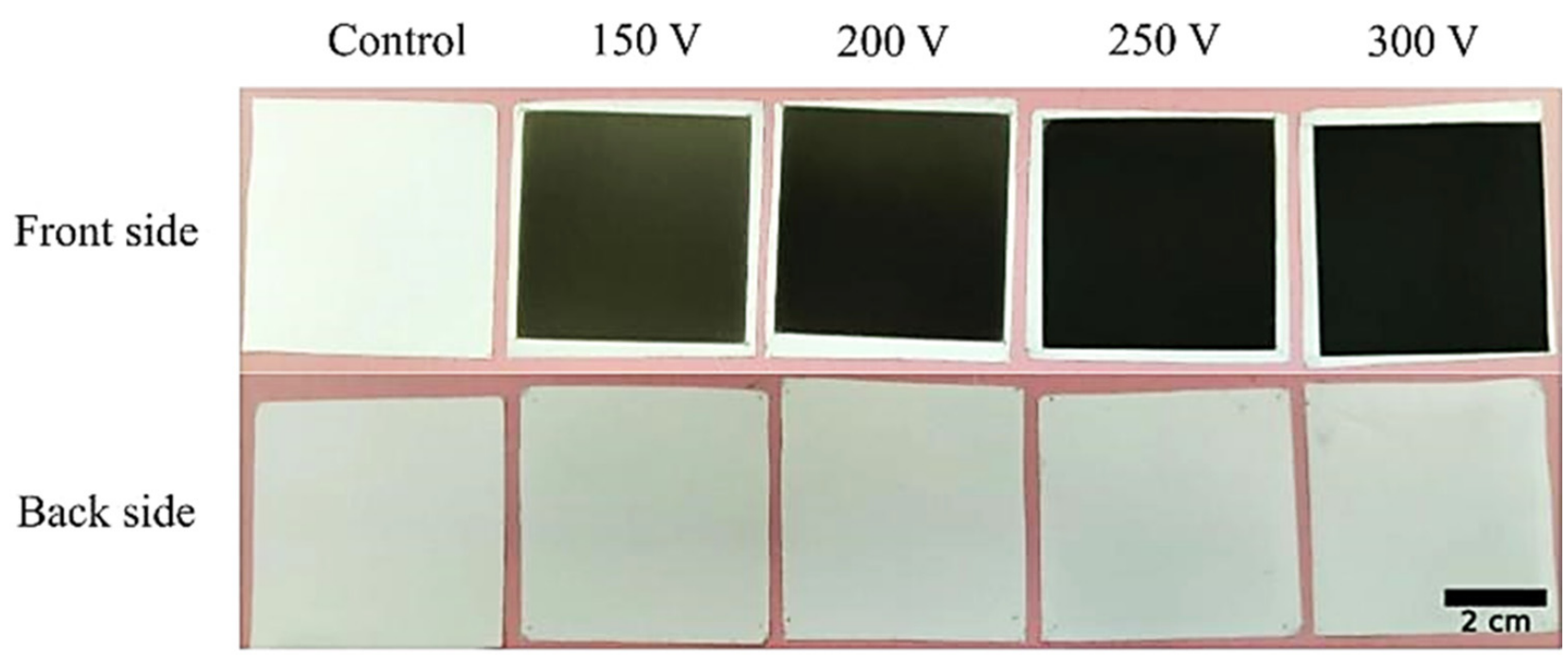

Figure 1. The photographs of the front and back sides of the membranes after the deposition of DLC coating under various capacitor storage voltages.

\subsection{Scanning Electron Microscopy (SEM)}

SEM images of the membrane surface before and after DLC coating deposition are presented in Figure 2. Control membranes were formed by chaotically interwoven cylindrical fibers. Fiber defects (such as beading and thickening) were not observed. At higher magnifications, the fibers' microrelief may be observed. It is presented by cavities directed along the fiber and uniformly distributed along the fiber surface. Average fiber diameter was found to be $0.61 \pm 0.21 \mu \mathrm{m}$. Coating deposition under the tested parameters did not result in changes to the membrane structure. The fibers remained sustained and defects were not observed.

An increase in the capacitor storage voltage resulted in changes in the fibers' surface relief. At $150 \mathrm{~V}$, a number of cavities were observed on the smooth fibers' surfaces (Figure $2 b$ ). At $300 \mathrm{~V}$, these cavities were filled and the fiber diameter increased slightly (Table 1). Thus, the presented results demonstrate the highest coating deposition rate within a voltage range of $250-300 \mathrm{~V}$.

Table 1. Average fiber diameter and mechanical characteristics of the membranes modified under various conditions.

\begin{tabular}{cccc}
\hline Capacitor Storage Voltage, $\mathbf{V}$ & Mean Fiber Diameter, $\boldsymbol{\mu m}$ & Tensile Strength, MPa & Elongation, \% \\
\hline 0 & $0.61 \pm 0.21$ & $17.8 \pm 1.8$ & $65.3 \pm 9.0$ \\
150 & $0.57 \pm 0.24$ & $15.7 \pm 0.7^{*}$ & $63.0 \pm 4.7$ \\
200 & $0.56 \pm 0.21$ & $14.8 \pm 0.5^{*}$ & $61.7 \pm 3.6$ \\
250 & $0.63 \pm 0.22$ & $14.0 \pm 0.4^{*}$ & $56.6 \pm 2.6^{*}$ \\
300 & $0.67 \pm 0.19^{*}$ & $14.3 \pm 1.1^{*}$ & $42.2 \pm 1.9^{*}$ \\
\hline
\end{tabular}

${ }^{*}, p<0.05$ compared to control (Kruskal-Wallis test). 

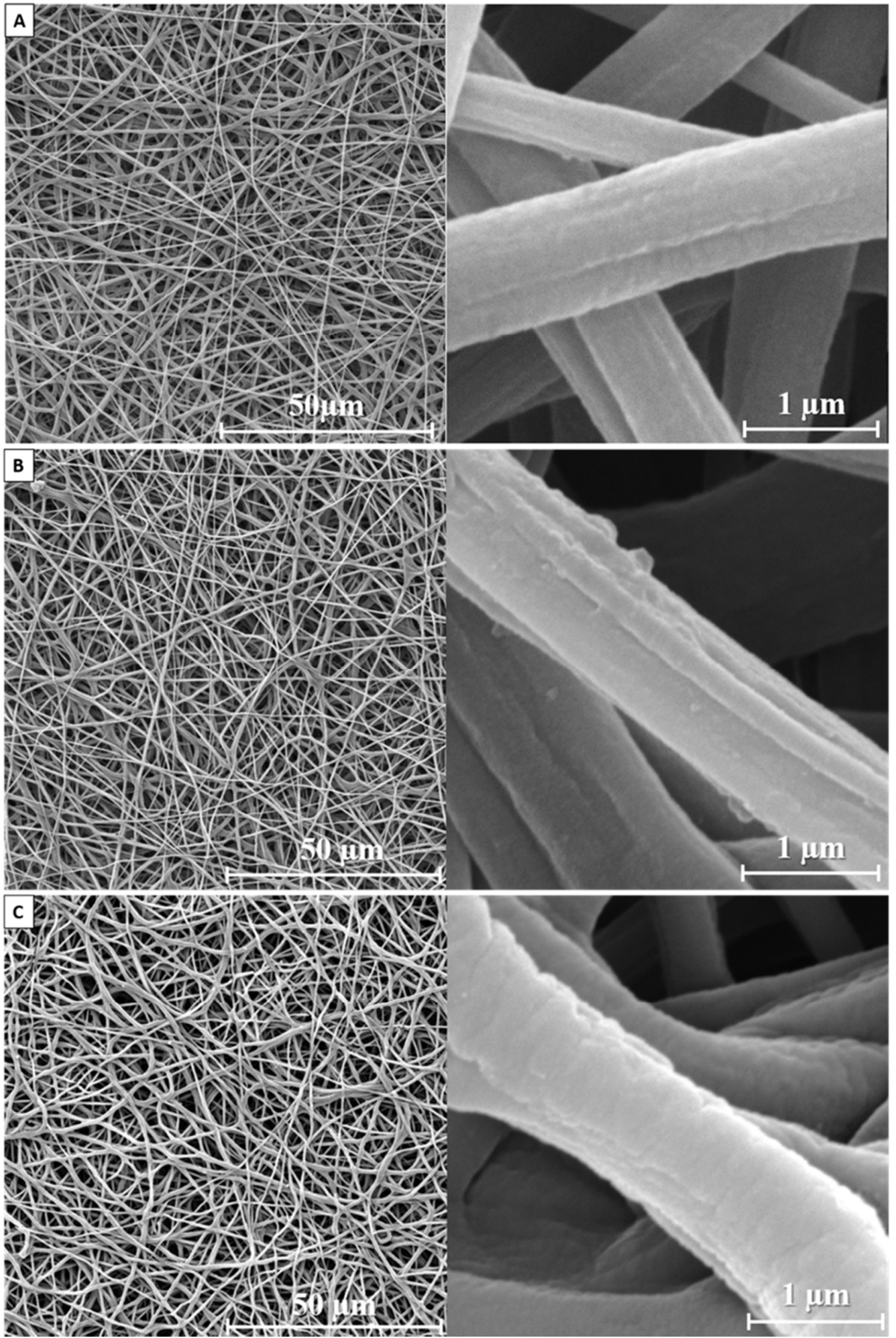

Figure 2. SEM images of the front membrane surface: (A) - non-treated, (B) - $150 \mathrm{~V},(\mathbf{C})-300 \mathrm{~V}$.

\subsection{Tensile Strength and Relative Elongation}

The ultimate tensile strength and relative elongation of the intact membrane under longitudinal strain were found at $17.8 \pm 1.8 \mathrm{MPa}$ and $65.3 \pm 9.0 \%$, respectively. DLC coating formation resulted in a decrease in the membrane strength and elongation in all studied groups. The maximum decrease was observed for the samples coated under capacitor storage voltages of 250 and $300 \mathrm{~V}$ (Table 1). A decrease in the membranes' 
strength and relative elongation with the voltage increase may be explained as follows: A voltage increase in the range of 100-400 V results in a decrease in the energy of carbon ions from 30 to $90 \mathrm{eV}$ [25]. The interaction of high-energy ions with polymer fibers leads to the formation of surface defects. The sizes and amount of the formed defects are proportional to the ion energy [26]. As the strength of ultrathin fibers is significantly affected by their surface properties [27], it may be proposed that the formation of defects on the front side of the membranes significantly reduces their strength and elongation.

\subsection{X-ray Diffraction Analysis}

$X$-ray diffraction patterns of the untreated membranes and the samples with deposited DLC coating are presented in Figure 3. The XRD pattern of the pristine VDF-TeFE membrane exhibits an intense peak at $19.3^{\circ}$, corresponding to the (110) crystallographic plane, and a broad peak at $34.6^{\circ}$, corresponding to the (001) crystallographic plane of the electrically active $\beta$ phase of the VDF-TeFE copolymer [28]. The presence of the $\beta$ phase indicates ferroelectric and piezoelectric properties in the produced polymer membranes [29]. The formation of electrically active crystalline phases in electrospun non-woven materials based on polyvinylidene fluoride and its copolymers is caused by the polarization of the polymer under the influence of a high-intensity electric field in the space between the needle and the collector [30]. Unlike the DLC coatings deposited using the reactive magnetron sputtering method, the coatings obtained using the pulsed vacuum arc deposition technique were found to be amorphous regardless of the capacitor storage voltage. This finding is confirmed by the absence of reflexes at $43.2^{\circ}, 44.3^{\circ}$, and $50.4^{\circ}$, corresponding to diamond, carbon, and graphite, respectively [31]. The fabrication of DLC coatings under the tested parameters had no effect on the crystal structure of the VDF-TeFE membranes, which is evidenced by the absence of statistically significant changes in $\beta$ phase crystallite sizes in the (110) crystallographic plane. The absence of $\beta$ phase reflexes proves the preservation of interplanar spacing (Figure 3).

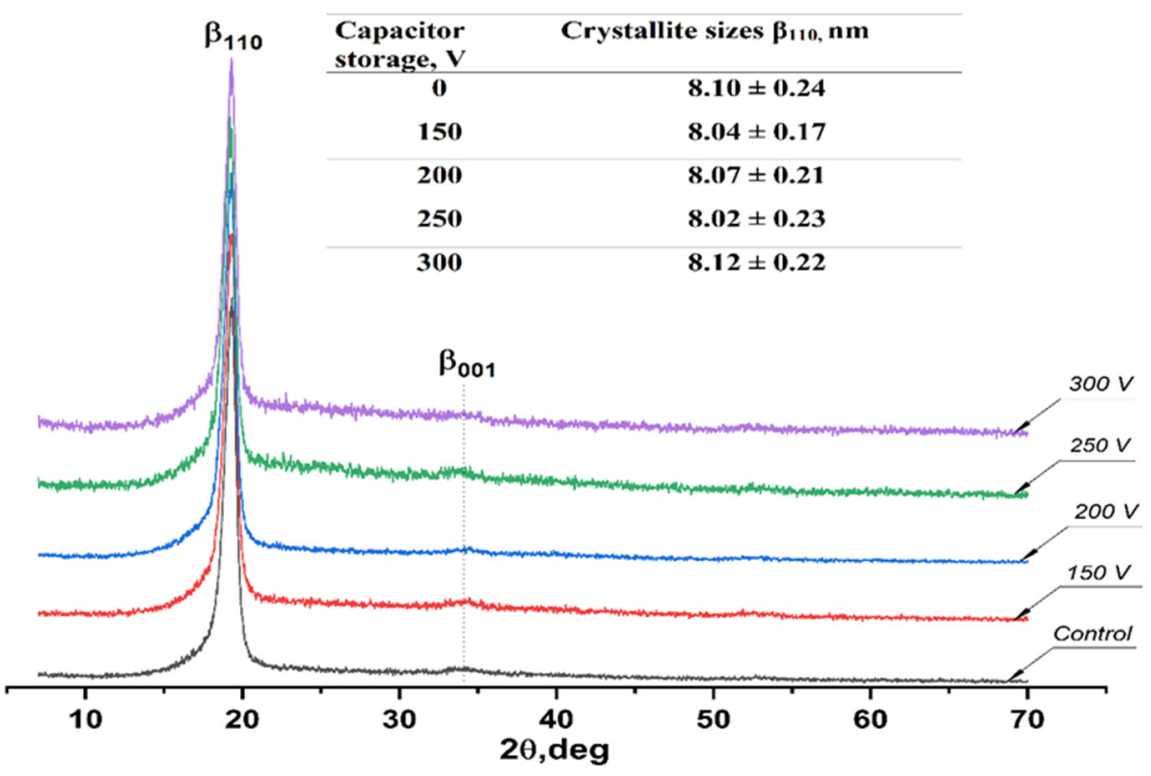

Figure 3. X-ray diffraction patterns of the obtained membranes.

Thus, it was found that during the DLC coating deposition, polymer membranes preserve their ferroelectric and piezoelectric crystal structure. This finding may be useful for drug delivery and the active stimulation of membrane-native tissue integration $[32,33]$.

\subsection{Raman Spectroscopy}

The Raman spectra of the obtained materials are presented in Figure 4. The spectrum of the initial polymer membrane presents a number of intensive bands. A strong Raman 
band at $834 \mathrm{~cm}^{-1}$ is assigned to the symmetric stretching mode of the $\mathrm{CF}_{2}$ groups in the all-trans (TTT) conformation. The band at $885 \mathrm{~cm}^{-1}$ is characteristic of the VDF monomeric unit, which is assigned to the $\mathrm{CH}_{2}$ rocking mode. The Raman band at $1280 \mathrm{~cm}^{-1}$ (a coupling of $\mathrm{CF}_{2}$ stretching and skeletal $\mathrm{C}-\mathrm{C}$ stretching modes) is also characteristic of the all-trans conformation. The band at $1430 \mathrm{~cm}^{-1}$ is assigned to the $-\mathrm{CH} 2$ deformation mode characteristic of the VDF sequence. The band at $1330 \mathrm{~cm}^{-1}$ is assigned to the C-C stretching mode characteristic of the VDF sequence [34-36]. The absence of a Raman band at $810 \mathrm{~cm}^{-1}$, attributed to the gauche form, confirms our conclusions on polymer $\beta$ phase crystallization based on XRD results. Two wide bands may be observed on the spectra of the samples with DLC coatings. The first one is an intensive band in the range of $1000-1750 \mathrm{~cm}^{-1}$ corresponding to the G and D peaks' (1560 and $1360 \mathrm{~cm}^{-1}$, respectively) superposition. The $\mathrm{G}$ and $\mathrm{D}$ peaks are due to $\mathrm{sp}^{2}$ bonded carbon atoms. The $\mathrm{G}$ peak is due to the bond stretching of all pairs of $\mathrm{sp}^{2}$ atoms in both rings and chains. The $\mathrm{D}$ peak is due to the "breathing" modes of $\mathrm{sp}^{2}$ atoms in rings, or to an $\mathrm{sp}^{3}$ network structure. That wide peak is typical for amorphous carbon structures $[37,38]$. The second, less intensive band lies in the range of $1820-2200 \mathrm{~cm}^{-1}$ and corresponds to the linear polymeric sp-hybridized carbon chain (carbynes), either in the form of cumulenes $(C=C) n$, or as polyynes $(C \equiv C) n$, which are known to have Raman bands in the spectral range associated with the stretching vibrations of $C=C$ bonds $[39,40]$. With the increase in the capacitor storage voltage, the $G$ peak shifted toward higher wavenumbers, an increase in the intensity of the $D$ peak, and the $\mathrm{I}_{\mathrm{D}} / \mathrm{I}_{\mathrm{G}}$ ratio was observed (Figure 4 , Table 2 ).

Table 2. Parameters of Raman spectra of the obtained materials.

\begin{tabular}{cccc}
\hline Voltage, $\mathbf{V}$ & G-Peak Position, $\mathbf{c m}^{-\mathbf{1}}$ & $\mathbf{I}_{\mathbf{D}} / \mathbf{I}_{\mathbf{G}}$ & $\mathbf{I}_{\mathbf{m a x}} / \mathbf{I}_{\mathbf{C}}$ \\
\hline 150 & 1556 & $0.46 \pm 0.11$ & $7.24 \pm 0.58$ \\
\hline 200 & 1561 & $0.50 \pm 0.14$ & $4.32 \pm 0.32{ }^{*}$ \\
\hline 250 & 1558 & $0.55 \pm 0.12 *$ & $4.19 \pm 0.28^{*}$ \\
\hline 300 & 1566 & $0.70 \pm 0.18^{*}$ & $4.35 \pm 0.36^{*}$ \\
\hline
\end{tabular}

${ }^{*}, p<0.05$ compared to the control (Kruskal-Wallis test).

These changes in Raman spectra are caused by the clustering of atoms having $\mathrm{sp}^{2}$ hybridization. Therefore, the increase in the capacitor storage voltage favors the rearrangement of the amorphous matrix, which leads to an increased number of closed carbon rings in $\mathrm{sp}^{2}$ clusters and/or the number of clusters containing rings [24]. The decrease in the $\mathrm{I}_{\max } / \mathrm{I}_{\mathrm{C}}$ ratio with the voltage rise (Table 2 ) is most likely due to the increase in the length of cumulene-like chains $(=C=C=)$ and/or the formation of polyyne-like chains $(-C \equiv C-)$, and may occur as a result of DLC crystal structure rearrangement under the greater energy of carbon plasma ions [24]. Thus, the conducted studies demonstrate the possibility of DLC coating composition control accompanied by the preservation of the membrane structure. 


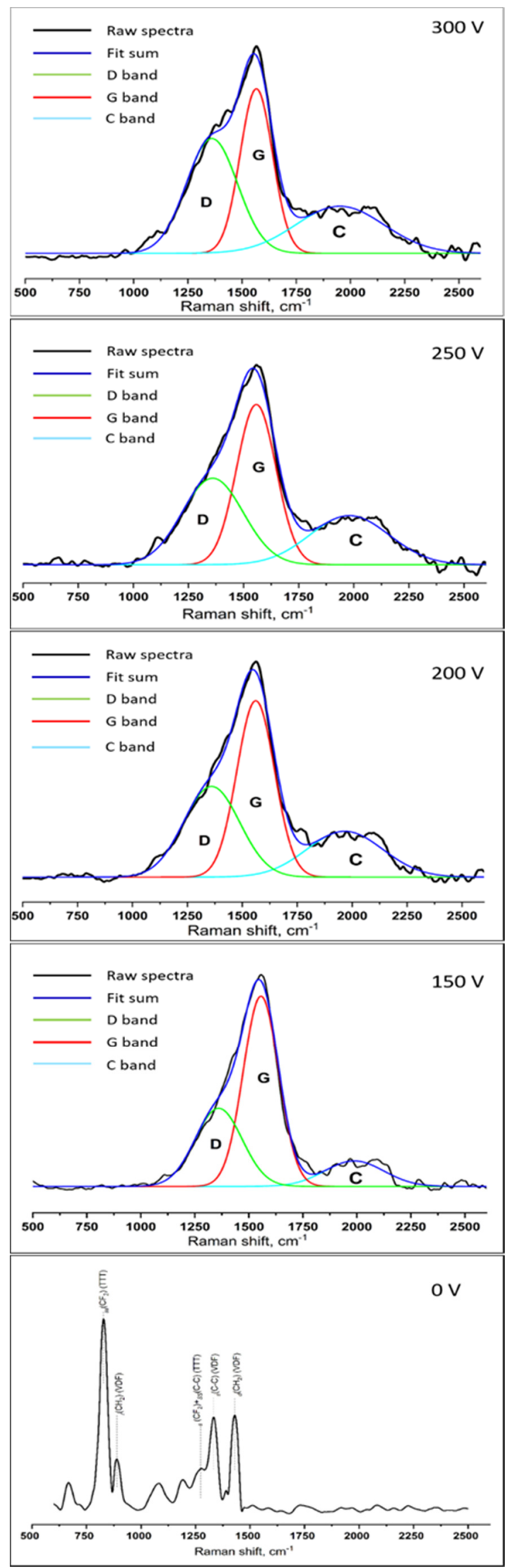

Figure 4. Raman spectra of the obtained membranes. 


\subsection{Wettability and Surface Energy}

The water and diiodomethane contact angles of the obtained membranes, as well as the surface energy $(\sigma)$ and its dispersive $\left(\sigma^{\mathrm{D}}\right)$ and polar $\left(\sigma^{\mathrm{P}}\right)$ components, were calculated using the OWRK method and are presented in Table 3. Non-modified membranes demonstrate extremely low surface free energy (Table 3), which is due to the low electronegativity of fluorine and the high porosity and heterogeneity of the membrane surface [41,42]. The DLC coatings deposited on the membrane surface had no effect on the water contact angle. The diiodomethane contact angle decreased $75 \%$ and $88 \%$ in the case of coatings deposited under 150 and $300 \mathrm{~V}$, respectively (Table 3). The decrease in the non-polar liquid contact angle evidences an increase in the DLC-coated membranes' surface free energy of more than 10 times compared to the control (Table 3).

Table 3. Contact angles and free surface energy of the membranes with DLC coatings deposited under various parameters.

\begin{tabular}{cccccc}
\hline \multirow{2}{*}{ Voltage, $\mathbf{V}$} & \multicolumn{2}{c}{ Contact Angle, Degrees } & \multicolumn{3}{c}{ Surface Free Energy, $\mathbf{~ J J / \mathbf { m } ^ { 2 }}$} \\
\cline { 2 - 6 } & $\mathbf{H}_{\mathbf{2}} \mathbf{O}$ & $\mathbf{C H}_{\mathbf{2}} \mathbf{I}_{\mathbf{2}}$ & $\boldsymbol{\sigma}$ & $\mathbf{\sigma}^{\mathbf{D}}$ & $\mathbf{\sigma}^{\mathbf{P}}$ \\
\hline 0 & $130.6 \pm 2.0$ & $109.1 \pm 2.2$ & $5.8 \pm 0.2$ & $5.7 \pm 0.2$ & $0.06 \pm 0.02$ \\
\hline 150 & $126.0 \pm 1.7$ & $24.2 \pm 3.4^{*}$ & $66.3 \pm 1.4$ & $58.0 \pm 1.1$ & $8.3 \pm 0.3$ \\
\hline 200 & $126.1 \pm 1.8$ & $12.4 \pm 1.8^{*}$ & $71.8 \pm 0.8$ & $62.4 \pm 0.6$ & $9.4 \pm 0.2$ \\
\hline 250 & $127.1 \pm 0.7$ & $11.2 \pm 2.0^{*}$ & $73.0 \pm 0.8$ & $63.0 \pm 0.7$ & $10.0 \pm 0.3$ \\
\hline 300 & $128.1 \pm 0.9$ & $12.6 \pm 2.0^{*}$ & $73.4 \pm 0.9$ & $63.0 \pm 0.7$ & $10.5 \pm 0.2$ \\
\hline
\end{tabular}

$*, p<0.05$ compared to the control (Kruskal-Wallis test).

The rise in free surface energy from its dispersive component was described by Kalin et al. [43] in the case of poly(tetrafluoroethylene). The increase in free surface energy after the deposition of the DLC coating may be due to the combined effects of non-polar interaction (or dispersive component) induced by $\mathrm{sp}^{2}$ bonds, and polar interaction by dangling bonds [44].

\subsection{Cytotoxicity of Membrane Extracts}

Micrographs of the cells cultured in the wells of 96-well plates with 5 day extracts of the obtained membranes with DLC coatings deposited under various conditions are presented in Figure 5.

After $24 \mathrm{~h}$ of cultivation, fusiform fibroblasts with well-defined round or oval nuclei were observed in all studied groups. The cells were conglomerated in clusters with the square up to $0.03 \mathrm{~mm}^{2}$. Cell viability parameters were not significantly different between the studied groups (Table 4). After $72 \mathrm{~h}$ of cultivation, the cells remained fusiform and highly viable. This is evidenced by the 2.5 -fold increase in the cell density in comparison with $24 \mathrm{~h}$ of cultivation (Table 4). After $168 \mathrm{~h}$ of cultivation, a confluent fibroblast monolayer was formed in all studied groups (Figure 5). After $168 \mathrm{~h}$, viability characteristics were not significantly different compared to the control. 

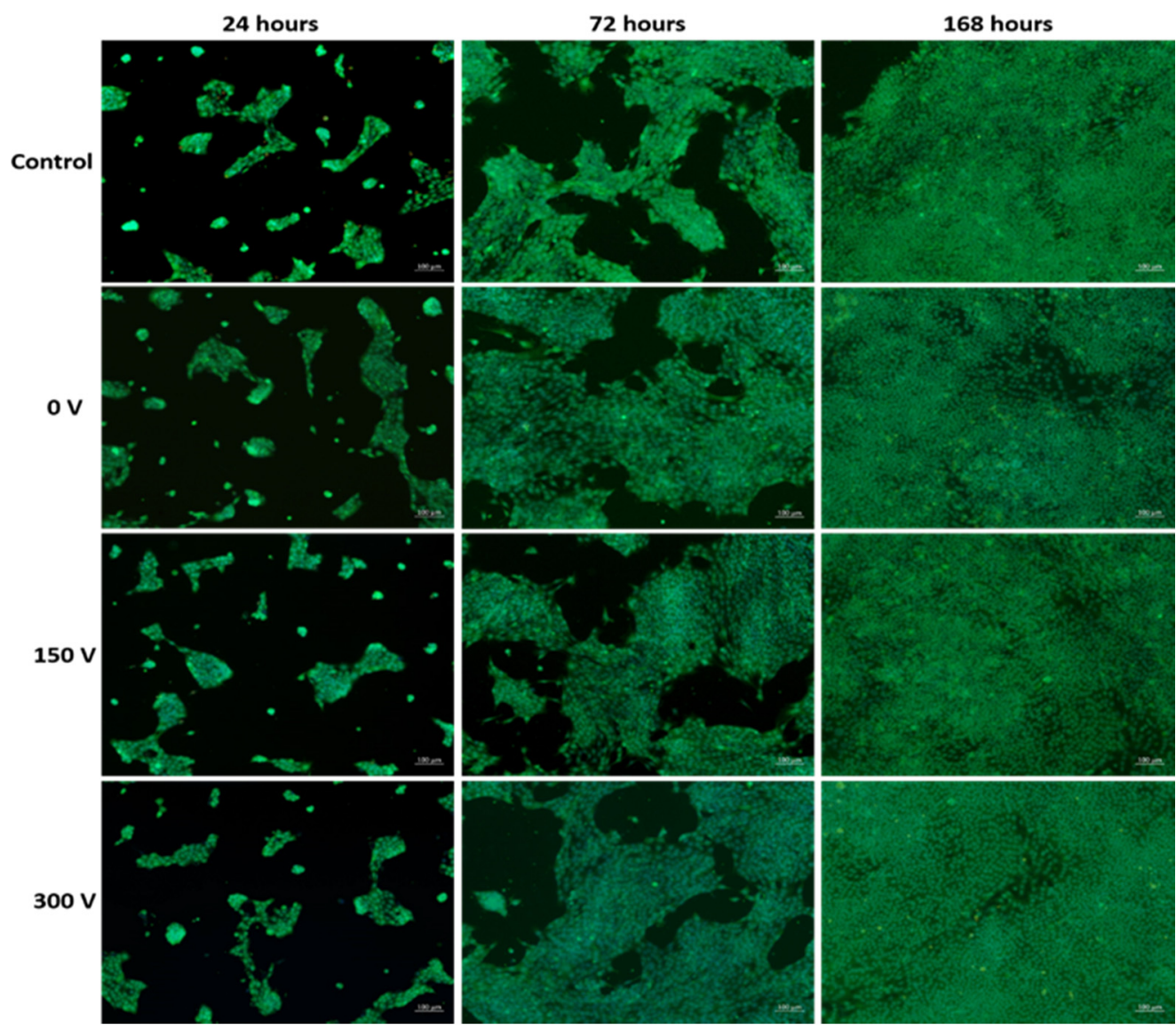

Figure 5. Images of the fluorescently labeled fibroblasts after 24, 72 and $120 \mathrm{~h}$ of cultivation with sample extracts.

Table 4. Results of testing the cytotoxicity of obtained membranes after 24,72 , and $168 \mathrm{~h}$ of cultivation.

\begin{tabular}{|c|c|c|c|c|c|c|}
\hline \multirow{2}{*}{ Voltage, V } & $\begin{array}{l}\text { Number of } \\
\text { Cells, } \mathbf{m m}^{-2}\end{array}$ & $\begin{array}{c}\text { Cell Viability, } \\
\%\end{array}$ & $\begin{array}{l}\text { Number of } \\
\text { Cells, } \mathbf{m m}^{-2}\end{array}$ & $\begin{array}{c}\text { Cell Viability, } \\
\%\end{array}$ & $\begin{array}{l}\text { Number of } \\
\text { Cells, } \text { mm }^{-2}\end{array}$ & $\begin{array}{c}\text { Cell Viability, } \\
\%\end{array}$ \\
\hline & \multicolumn{2}{|c|}{$24 \mathrm{~h}$} & \multicolumn{2}{|c|}{$72 \mathrm{~h}$} & \multicolumn{2}{|c|}{$168 \mathrm{~h}$} \\
\hline 0 & $225 \pm 19$ & $103 \pm 5$ & $615 \pm 61$ & $100 \pm 8$ & $924 \pm 74$ & $98 \pm 9$ \\
\hline 150 & $222 \pm 18$ & $106 \pm 8$ & $631 \pm 48$ & $109 \pm 7$ & $977 \pm 54$ & $97 \pm 6$ \\
\hline 200 & $203 \pm 14$ & $106 \pm 6$ & $634 \pm 57$ & $105 \pm 9$ & $953 \pm 63$ & $99 \pm 10$ \\
\hline 250 & $223 \pm 17$ & $105 \pm 8$ & $663 \pm 44$ & $96 \pm 10$ & $989 \pm 77$ & $101 \pm 6$ \\
\hline 300 & $208 \pm 22$ & $99 \pm 10$ & $655 \pm 52$ & $94 \pm 12$ & $932 \pm 68$ & $103 \pm 5$ \\
\hline Control & $216 \pm 31$ & $100 \pm 5$ & $636 \pm 49$ & $100 \pm 6$ & $932 \pm 61$ & $99 \pm 4$ \\
\hline
\end{tabular}

The slight decrease in cell viability after $168 \mathrm{~h}$ of cultivation, compared to a 24 -h period, is the result of culture medium depletion and the accumulation of cell waste products. Thus, the conducted studies demonstrate that, regardless of the parameters for DLC coating deposition, the modified membranes have high biocompatibility and contain no toxic compounds, which are able to suppress 3T3L1 fibroblast growth.

\section{Conclusions}

The possibility of DLC coating deposition on the surface of ferroelectric polymer membranes by means of pulsed vacuum arc deposition was demonstrated. The obtained materials are promising for the development of vascular patches. It was shown that DLC coatings formed on the front side of the membrane do not change its macrostructure, preserving its high strength and elongation, and are an efficient tool for surface modification. DLC coatings formed under the studied parameters were found to be amorphous. The 
process of DLC coating deposition had no effect on the membranes' crystal structure, thus preserving its ferroelectric properties. It was revealed that with the increase in capacitor storage voltage, the concentration of $\mathrm{sp}^{2}$ and sp-hybridized carbon in the coating rises. Thus, it is possible to vary the chemical composition and surface energy of the membrane. Extracts of the obtained membranes were found to be non-toxic to 3T3L1 fibroblasts and did not affect cell proliferation.

Supplementary Materials: The following are available online at https:/ / www.mdpi.com/article/ $10.3390 /$ membranes11090690/s1, Figure S1: Layout of membrane samples in the chamber of the pulsed vacuum arc deposition.

Author Contributions: Conceptualization, E.B.; data curation, E.P. (Elisaveta Prosetskaya); formal analysis, Y.Y., S.G. and E.P. (Evgenii Plotnikov); Investigation, Y.Y., S.G., A.R., E.P. (Elisaveta Prosetskaya), E.P. (Evgenii Plotnikov), D.S. and Y.K.; methodology, E.P. (Evgenii Plotnikov) and D.S.; resources, Y.K. and E.B.; supervision, E.B.; visualization, A.R.; writing-original draft, Y.Y., S.G. and E.B. All authors have read and agreed to the published version of the manuscript.

Funding: The study was supported by Russian Science Foundation (project number 21-73-20262).

Institutional Review Board Statement: Not applicable.

Informed Consent Statement: Not applicable.

Data Availability Statement: Not applicable.

Conflicts of Interest: The authors declare no conflict of interest.

\section{References}

1. Bonati, L.; Dobson, J.; Featherstone, R.L.; Ederle, J.; van der Worp, H.B.; de Borst, G.J.; Mali, W.P.T.M.; Beard, J.D.; Cleveland, T.; Engelter, S.; et al. Long-term outcomes after stenting versus endarterectomy for treatment of symptomatic carotid stenosis: The International Carotid Stenting Study (ICSS) randomised trial. Lancet 2015, 385, 529-538. [CrossRef]

2. Kaptoge, S.; Pennells, L.; De Bacquer, D.; Cooney, M.T.; Kavousi, M.; Stevens, G.; Riley, L.M.; Savin, S.; Khan, T.; Altay, S.; et al. World Health Organization cardiovascular disease risk charts: Revised models to estimate risk in 21 global regions. Lancet Glob. Health 2019, 7, e1332-e1345. [CrossRef]

3. Hanff, T.C.; Mohareb, A.M.; Giri, J.; Cohen, J.; Chirinos, J.A. Thrombosis in COVID-19. Am. J. Hematol. 2020, 95, 1578-1589. [CrossRef] [PubMed]

4. Naylor, A.; Ricco, J.-B.; De Borst, G.; Debus, S.; De Haro, J.; Halliday, A.; Hamilton, G.; Kakisis, J.; Kakkos, S.; Lepidi, S.; et al. Editor's Choice-Management of Atherosclerotic Carotid and Vertebral Artery Disease: 2017 Clinical Practice Guidelines of the European Society for Vascular Surgery (ESVS). Eur. J. Vasc. Endovasc. Surg. 2018, 55, 3-81. [CrossRef]

5. Muto, A.; Nishibe, T.; Dardik, H.; Dardik, A. Patches for carotid artery endarterectomy: Current materials and prospects. J. Vasc. Surg. 2009, 50, 206-213. [CrossRef] [PubMed]

6. Arumugam, R.; Srinadhu, E.S.; Subramanian, B.; Nallani, S. $\beta$-PVDF based electrospun nanofibers-A promising material for developing cardiac patches. Med. Hypotheses 2019, 122, 31-34. [CrossRef]

7. Augustine, R.; Dan, P.; Sosnik, A.; Kalarikkal, N.; Tran, N.; Vincent, B.; Thomas, S.; Menu, P.; Rouxel, D. Electrospun poly(vinylidene fluoride-trifluoroethylene)/zinc oxide nanocomposite tissue engineering scaffolds with enhanced cell adhesion and blood vessel formation. Nano Res. 2017, 10, 3358-3376. [CrossRef]

8. Hitscherich, P.; Wu, S.; Gordan, R.; Xie, L.-H.; Arinzeh, T.; Lee, E.J. The effect of PVDF-TrFE scaffolds on stem cell derived cardiovascular cells. Biotechnol. Bioeng. 2016, 113, 1577-1585. [CrossRef]

9. Lv, J.; Cheng, Y. Fluoropolymers in biomedical applications: State-of-the-art and future perspectives. Chem. Soc. Rev. 2021, 50, 5435-5467. [CrossRef]

10. Zhang, S.; Cao, J.; Ma, N.; You, M.; Wang, X.; Meng, J. Fast and facile fabrication of antifouling and hemocompatible PVDF membrane tethered with amino-acid modified PEG film. Appl. Surf. Sci. 2018, 428, 41-53. [CrossRef]

11. Okuji, S.; Kitazawa, H.; Takeda, Y. Time of flight-secondary ion mass spectrometry analysis of protein adsorption on a polyvinylidene difluoride surface modified by ion irradiation. Colloids Surf. B Biointerfaces 2016, 148, 249-254. [CrossRef]

12. Jiang, J.; Zhang, P.; Zhu, L.; Zhu, B.; Xu, Y. Improving antifouling ability and hemocompatibility of poly(vinylidene fluoride) membranes by polydopamine-mediated ATRP. J. Mater. Chem. B 2015, 3, 7698-7706. [CrossRef]

13. Liu, T.-Y.; Lin, W.-C.; Huang, L.-Y.; Chen, S.-Y.; Yang, M.-C. Surface characteristics and hemocompatibility of PAN/PVDF blend membranes. Polym. Adv. Technol. 2005, 16, 413-419. [CrossRef]

14. Grenadyorov, A.; Solovyev, A.; Ivanova, N.; Zhulkov, M.; Chernyavskiy, A.; Malashchenko, V.; Khlusov, I. Enhancement of the adhesive strength of antithrombogenic and hemocompatible a-C:H:SiOx films to polypropylene. Surf. Coat. Technol. 2020, 399, 126132. [CrossRef] 
15. Al-Jumaili, A.; Alancherry, S.; Bazaka, K.; Jacob, M.V. Review on the Antimicrobial Properties of Carbon Nanostructures. Materials 2017, 10, 1066. [CrossRef] [PubMed]

16. Narayan, R. Diamond-Based Materials for Biomedical Applications; Elsevier: Amsterdam, The Netherlands, 2013.

17. Kaneko, M.; Hiratsuka, M.; Alanazi, A.; Nakamori, H.; Namiki, K.; Hirakuri, K. Surface Reformation of Medical Devices with DLC Coating. Materials 2021, 14, 376. [CrossRef] [PubMed]

18. Gotzmann, G.; Beckmann, J.; Scholz, B.; Herrmann, U.; Wetzel, C. Low-energy electron-beam modification of DLC coatings reduces cell count while maintaining biocompatibility. Surf. Coat. Technol. 2018, 336, 34-38. [CrossRef]

19. Penkov, O.; Kheradmandfard, M.; Khadem, M.; Kharaziha, M.; Mirzaamiri, R.; Seo, K.-J.; Kim, D.-E. Ion-beam irradiation of DLC-based nanocomposite: Creation of a highly biocompatible surface. Appl. Surf. Sci. 2019, 469, 896-903. [CrossRef]

20. Ohtake, N.; Hiratsuka, M.; Kanda, K.; Akasaka, H.; Tsujioka, M.; Hirakuri, K.; Hirata, A.; Ohana, T.; Inaba, H.; Kano, M.; et al. Properties and Classification of Diamond-Like Carbon Films. Materials 2021, 14, 315. [CrossRef]

21. Vetter, J. 60 years of DLC coatings: Historical highlights and technical review of cathodic arc processes to synthesize various DLC types, and their evolution for industrial applications. Surf. Coat. Technol. 2014, 257, 213-240. [CrossRef]

22. Poplavsky, A.; Kolpakov, A.; Kudriavtsev, Y.; Asomoza, R.; Goncharov, I.; Galkina, M.; Manokhin, S.; Kharchenko, V. Effect of nitrogen ion irradiation parameters on properties of nitrogen-containing carbon coatings prepared by pulsed vacuum arc deposition method. Vacuum 2018, 152, 193-199. [CrossRef]

23. Kolpakov, A.; Poplavsky, A.; Galkina, M.; Manokhin, S.S.; Gerus, J.V. The local crystallization in nanoscale diamond-like carbon films during annealing. Appl. Phys. Lett. 2014, 105, 233110. [CrossRef]

24. Poplavsky, A.; Kudriavtsev, Y.; Kolpakov, A.; Pilyuk, E.; Manokhin, S.; Goncharov, I. The effect of vacuum annealing on the structure and properties of the electrically conductive a-CN coating. Vacuum 2021, 184, 109919. [CrossRef]

25. Maslov, A.; Dmitriev, G.C.Y.D. Pulsed Carbon-Plasma Source for Production Processes. Instrum. Exp. Tech. $1985,28,662-667$.

26. Chan, C.M.; Ko, T.-M.; Hiraoka, H. Polymer surface modification by plasmas and photons. Surf. Sci. Rep. 1996, 24, 1-54. [CrossRef]

27. Park, J.H.; Rutledge, G.C. 50th Anniversary Perspective: Advanced Polymer Fibers: High Performance and Ultrafine. Macromolecules 2017, 50, 5627-5642. [CrossRef]

28. Kochervniskii, V.V.; Astakhov, V.A.; Bedin, S.A.; Malyshkina, I.A.; Shmakova, N.A.; Korlyukov, A.A.; Buzin, M.I.; Volkov, V.V. Peculiarities of structure and dielectric relaxation in ferroelectric vinylidene fluoride-tetrafluoroethylene copolymer at different crystallization conditions. Colloid Polym. Sci. 2020, 298, 1169-1178. [CrossRef]

29. Cui, Z.; Hassankiadeh, N.T.; Zhuang, Y.; Drioli, E.; Lee, Y.M. Crystalline polymorphism in poly(vinylidenefluoride) membranes. Prog. Polym. Sci. 2015, 51, 94-126. [CrossRef]

30. Badaraev, A.; Koniaeva, A.; Krikova, S.; Shesterikov, E.; Bolbasov, E.; Nemoykina, A.; Bouznik, V.; Stankevich, K.; Zhukov, Y.; Mishin, I.; et al. Piezoelectric polymer membranes with thin antibacterial coating for the regeneration of oral mucosa. Appl. Surf. Sci. 2020, 504, 144068. [CrossRef]

31. Qi, M.; Xiao, J.; Cheng, Y.; Wang, Z.; Jiang, A.; Guo, Y.; Tao, Z. Effect of various nitrogen flow ratios on the optical properties of (Hf:N)-DLC films prepared by reactive magnetron sputtering. AIP Adv. 2017, 7, 085012. [CrossRef]

32. Han, M.; Wang, H.; Yang, Y.; Liang, C.; Bai, W.; Yan, Z.; Li, H.; Xue, Y.; Wang, X.; Akar, B.; et al. Three-dimensional piezoelectric polymer microsystems for vibrational energy harvesting, robotic interfaces and biomedical implants. Nat. Electron. 2019, 2, 26-35. [CrossRef]

33. Tandon, B.; Magaz, A.; Balint, R.; Blaker, J.; Cartmell, S.H. Electroactive biomaterials: Vehicles for controlled delivery of therapeutic agents for drug delivery and tissue regeneration. Adv. Drug Deliv. Rev. 2018, 129, 148-168. [CrossRef]

34. Tashiro, K.; Kaito, H.; Kobayashi, M. Structural changes in ferroelectric phase transitions of vinylidene fluoride-tetrafluoroethylene copolymers: 1. Vinylidene fluoride content dependence of the transition behaviour. Polymer 1992, 33, 2915-2928. [CrossRef]

35. Tashiro, K.; Kobayashi, M. Vibrational spectroscopic study of the ferroelectric phase transition in vinylidene fluoridetrifluoroethylene copolymers: 1. Temperature dependence of the Raman spectra. Polymer 1988, 29, 426-436. [CrossRef]

36. Nakagawa, Y.; Hashizume, Y.; Nakajima, T.; Okamura, S. Ferroelectric properties of vinylidene fluoride/tetrafluoroethylene copolymer thin films consisting of needle-like crystals. Jpn. J. Appl. Phys. 2016, 55, 51601. [CrossRef]

37. Srinivasan, S.; Tang, Y.; Li, Y.; Yang, Q.; Hirose, A. Ion beam deposition of DLC and nitrogen doped DLC thin films for enhanced haemocompatibility on PTFE. Appl. Surf. Sci. 2012, 258, 8094-8099. [CrossRef]

38. Robertson, J. Diamond-like amorphous carbon. Mater. Sci. Eng. R Rep. 2002, 37, 129-281. [CrossRef]

39. Ivanenko, I.P.; Krasnoshchekov, S.V.; Pavlikov, A.V. Analysis of the Structure and Conductivity of Kinked Carbon Chains Obtained by Pulsed Plasma Deposition on Various Metal Substrates. Semiconductors 2018, 52, 907-913. [CrossRef]

40. Hu, A.; Rybachuk, M.; Lu, Q.-B.; Duley, W.W. Femtosecond pulsed laser deposition and optical properties of diamond-like amorphous carbon films embedded with sp-bonded carbon chains. Diam. Relat. Mater. 2008, 17, 1643-1646. [CrossRef]

41. Cui, Z.; Drioli, E.; Lee, Y.M. Recent progress in fluoropolymers for membranes. Prog. Polym. Sci. 2014, 39, 164-198. [CrossRef]

42. Cassie, A.B.D.; Baxter, S. Wettability of porous surfaces. Trans. Faraday Soc. 1944, 40, 546-551. [CrossRef]

43. Kalin, M.; Polajnar, M. The wetting of steel, DLC coatings, ceramics and polymers with oils and water: The importance and correlations of surface energy, surface tension, contact angle and spreading. Appl. Surf. Sci. 2014, 293, 97-108. [CrossRef]

44. Rahman, S.M.; Song, J.; Yeo, C.-D. Computational study on surface energy of amorphous DLC with respect to hybridization state of carbon and potential functions. Diam. Relat. Mater. 2019, 95, 127-134. [CrossRef] 